\title{
ANÁLISE DE CONTEÚDOS EM COLEÇÕES DE SISTEMAS APOSTILADOS DE ENSINO DE LÍNGUA INGLESA PARA OS ANOS INICIAIS DO ENSINO FUNDAMENTAL: O DISCURSO E A PRÁTICA ${ }^{1}$
}

\author{
Ticiane Rafaela de Andrade Moreno² (PG/PPGEL- UEL) \\ Prof ${ }^{a}$. Dra. Juliana Reichert Assunção Tonelli ${ }^{3}$ (Orientadora - UEL)
}

\section{RESUMO}

Neste trabalho, que remonta a nossa monografia de especialização, analisamos duas coleções didáticas, a Coleção Expoente e a Coleção Anglo, utilizadas no ano de 2013 nos municípios de Ourinhos e Jacarezinho respectivamente, como importante recurso didático para o ensino de inglês nos anos iniciais do ensino fundamental. A pesquisa é qualitativa, documental e do ponto de vista do material (RAMOS, 2009), analisando especificamente os conteúdos, traçando um paralelo entre livro do aluno e manual do professor. De acordo com as pesquisas sobre ensino de língua inglesa para crianças, os conteúdos trabalhados devem ser os gêneros textuais/discursivos (TONELLI, 2007; CRISTOVÃO, GAMERO, 2009) agrupados em três esferas discursivas: gêneros que fazem narrar, gêneros que fazem brincar e gêneros que fazem cantar (ROCHA, 2007, 2008, 2009, 2010), além de favorecerem os letramentos múltiplos, o plurilinguismo, a transculturalidade, a agentividade, entre outros (ROCHA, 2010). Em contrapartida, o que observamos no material são conteúdos descontextualizados, monofônicos, descontínuos, composto por léxico e estruturas linguísticas e que são divergentes em relação ao manual do professor e do livro do aluno.

Palavras-chave: Ensino de língua inglesa para crianças, sistemas apostilados de ensino, gêneros textuais/discursivos.

\section{INTRODUÇÃO}

O objetivo investigativo da nossa pesquisa foi analisar duas coleções didáticas de Sistemas Apostilados de Ensino: a Coleção Anglo e a Coleção Expoente sob a perspectiva, nesse presente artigo, dos conteúdos de Língua Inglesa para Crianças (LIC). Ambas as coleções foram utilizados por nós: a Coleção Anglo no interstício de 2011 a 2014 em uma escola particular no município de Jacarezinho (Paraná) e a Coleção Expoente em 2013 na rede municipal de Ourinhos (São Paulo). A partir de nossa prática, originaram-se nossas perguntas de pesquisa, visto que nossa formação inicial não nos proveu os subsídios necessários para atuar nesse segmento de educação, e durante algum tempo foram as apostilas o norte ou o sustento da nossa prática

\footnotetext{
${ }^{1}$ Este artigo é uma revisitação da nossa monografia de especialização "Read and Copy: o Ensino de Língua Inglesa para Crianças nos Sistemas Apostilados de Ensino", apresentada à Especialização em Ensino de Línguas Estrangeiras da UEL (MORENO, 2014), sob orientação da professora Dra. Marta A. Oliveira Balbino dos Reis, fruto de reflexões conjuntas com a coautora.

2 ticiane91@bol.com.br

${ }^{3}$ teacherjuliana@uol.com.br
} 


\section{SEMINÁRIO DE PESQUISA EM CIÊNCIAS HUMANAS - SEPECH \\ Humanidades, Estado e desafios didático-científicos \\ Londrina, 27 a 29 de julho de 2016}

didática. Assim, surgiu o interesse em deter um olhar investigativo a respeito de tais materiais para compreender como se prestavam em relação ao ensino de LIC.

Realizamos, então, um levantamento bibliográfico sobre as pesquisas de LIC desenvolvidas na contemporaneidade e que aportes teóricos, didáticos e metodológicos elas indicavam como caminhos para o ensino. Baseadas nessas leituras, nós confrontamos os materiais: o livro do aluno e do professor, realizando uma pesquisa qualitativa (COHEN, MANION, MORRISON, 2000 apud REIS, 2005) e documental (LÜDKE, ANDRÉ, 1986 apud LIMA, 2011), pois seu cunho é mais interpretativista e as apostilas são documentos analisados por nós. Diferentemente do que é realizado na escola, pretendemos aqui realizar uma avaliação de profundidade do ponto de vista do livro didático que pressupõe uma visão mais detalhada e que expõe os conflitos do mesmo (CUNNINGWORTH, 1995 apud RAMOS, ROSELLI, 2008) e do material, já que não abordaremos o seu uso em relação ao contexto vivo de sala de aula (RAMOS, 2009).

Os problemas vivenciados por nós são um reflexo da situação brasileira para o ensino de LIC na qual há um crescente aumento da oferta, visto que a língua inglesa é tida como um bem cultural e de ascensão social, mas ainda não há, dentro de um todo coerente e integrado, "bases mínimas comuns de referência, política e teoricamente sustentadas" (ROCHA TÍLIO, 2009, p. 296; ROCHA, 2010, p. 07) e "programas nacionais do livro didático específicos para esse contexto" (ROCHA, 2009, p. 172).

O ensino que não contempla a todos gera problemas de exclusão social (GIMENEZ, 2010), não só pelo valor mercadológico da língua, mas pelo potencial de tornar o "indivíduo plurilíngue e intercultural" (KING, MACKEY, 2007 apud SANTOS, 2010, p. 154), ou seja, de transpor e se apropriar de práticas culturais, além da sua própria e conhecer a diversidade linguística, não só de línguas, como de linguagens e variantes linguísticas, que tocam no cerne da diversidade humana.

Defendemos, por conseguinte, o ensino de LIC calcados em princípios emancipatórios, transformadores, éticos e protagonistas (ROCHA, 2010) que propiciem crescimento para o aluno e consequentemente sua inserção como cidadão dentro da sociedade. Para tanto, apontaremos conteúdos de LIC consonantes com essa proposta e como são apresentados dentro da lógica dos Sistemas Apostilados de Ensino.

Questionaremos, ainda, a crença geral na qualidade desses materiais. Isso porque a propaganda produzida pelas empresas e editoras que os produzem é muito intensa e atinge pais, professores, profissionais da escola, a comunidade em geral. Essa crença está imbricada com os problemas de avaliação gerados pelo vestibular que fazem com que cursinhos sejam mais valorizados do que escolas de educação infantil e séries iniciais e que o brincar, o criar, o imaginar, o discutir, o apreciar, o socializar sejam menosprezados em detrimento de uma preparação da criança para o vestibular.

O professor, em escolas que adotam os Sistemas Apostilados de Ensino, perde sua autonomia, pois o material vem com um sistema rígido de organização do trabalho de sala de aula e, em poucos contextos, pode transformá-lo de acordo com sua realidade, o que fere seus direitos assegurados pela LDB (CHIMELO, BUNZEN, 2011). Em casos mais graves, pode entrar no que Carmagnani (1999) ressignifica como panóptico foucaultiano, em que a apostila vigia o professor, o aluno e a escola e faz com que todo o trabalho docente esteja em permanente vigilância. Nesses contextos, a geração da aprendizagem é muito limitada. 


\section{SEMINÁRIO DE PESQUISA EM CIÊNCIAS HUMANAS - SEPECH \\ Humanidades, Estado e desafios didático-científicos \\ Londrina, 27 a 29 de julho de 2016}

\section{LÍNGUA INGLESA PARA CRIANÇAS: DISCUSSÃO ACERCA DOS CONTEÚDOS}

As pesquisas apontam que os conteúdos de ensino de LIC sejam sociodiscursivos, isto é, estejam contextualizados, permeados em um todo social, no qual a linguagem esteja situada, contemplando sua intencionalidade e dimensões valorativas para a comunidade ou sociedade em questão. De acordo com Bakhtin (1992), a comunicação se dá através de enunciados relativamente estabilizados através dos gêneros textuais/discursivos. Portanto, em LIC, o objeto e o instrumento do ensino são os gêneros (ROCHA, 2007a, 2007b, 2008, 2009, 2010); CRISTOVÃO, GAMERO, 2009; TONELLI, 2007).

A justificativa do ensino através dos gêneros textuais/discursivos em LIC se dá por esse possibilitar o desenvolvimento da proficiência em língua inglesa em que as práticas linguísticas estão permeadas sociohistoricamente; por suscitar atividades que envolvem o confronto do eu e do outro de forma a promover a aprendizagem, como as interações em sala de aula e a interculturalidade; e por problematizar esferas de comunicação habitadas pelo alunado e ampliar seus horizontes (ROCHA, 2007a). Assim, será fomentada uma leitura crítica de propagandas, desenhos animados, histórias, a desconstrução de estereótipos, preconceitos, discursos autoritários e reafirmação da identidade da criança (ROCHA, 2010).

Os gêneros que irão adentrar as salas de LIC serão, em sua maioria, proveniente da ideologia do cotidiano (ROCHA, 2010), sendo essa mais próxima do universo infantil, pois remete a oralidade e uso mais espontâneo e informal da língua, tornando a aprendizagem mais significativa. O processo de letramento de língua materna da criança também está em construção, principalmente no que concerne a aprendizagem formal dos registros escritos, aguardando, logo, o amadurecimento dessas habilidades para produzir gêneros secundários e escritos.

A criança não está só em contato com gêneros primários, como brincadeiras, músicas e danças; mas também está familiarizada com discursos complexos e de cunho ideológico desde muito cedo, como as artes plásticas, "filmes e vídeos, programas de TV, jogos de computadores" (EVANS, 2005, p. 01 apud ROCHA, 2010, p. 151). Por isso, não apenas os gêneros primários devem ser trabalhados, mas tudo que contribua para o letramento e desenvolvimento da criança (VYGOTSKY, 1984, 1998, p. 139 apud ROCHA, 2007a), sempre respeitando a Zona de Desenvolvimento Proximal. Podemos apontar as esferas de gêneros secundários também pertencentes ao universo infantil:

campo das artes (literatura infanto-juvenil, artes gráficas, da imagem etc.), da mídia digital (quando possível no contexto em que se insere o processo de ensino em questão) e da esfera do entretenimento, que permitam que esse aluno tenha acesso também a práticas letradas valorizadas, que ampliem seus conhecimentos e capacidades de agir de modo mais efetivo na sociedade em que vive. (ROCHA, 2010, p. 172)

De forma a apontar as esferas que poderiam estar mais presente no ensino de LIC, Rocha (2007a, 2007b, 2008, 2010) propõe um agrupamento de gêneros que relacionam três delas: gêneros que fazem brincar, o jogo, a dramatização, a brincadeira 


\section{SEMINÁRIO DE PESQUISA EM CIÊNCIAS HUMANAS - SEPECH \\ Humanidades, Estado e desafios didático-científicos \\ Londrina, 27 a 29 de julho de 2016}

e o brinquedo; gêneros que fazem cantar, músicas, cantigas e canções; gêneros que fazem contar contos de fadas, rimas infantis, lendas, entre outros. A familiaridade desses gêneros rompe com o estranhamento causado pela língua estrangeira, mesclando novas e antigas práticas sociais, em gêneros que são fortemente atravessados pelas culturas locais e as formas de produção populares. Além disso, Rocha (2008) aponta que tais esferas interpenetram-se e que o aluno pode "narrar cantando, contar brincando ou brincar narrando" (p. 26).

\section{ANÁLISE DOS MATERIAIS DIDÁTICOS}

A primeira coleção analisado por nós faz parte do Sistema Expoente de Ensino. Esse Sistema teve origem em uma escola localizada na cidade de Curitiba no ano de 1987. Os materiais são desenvolvidos para públicos desde a Educação Infantil até o Prévestibular, também apresentando uma coleção para EJA (Educação de Jovens e Adultos). O Sistema frisa muito a preparação dos alunos para exames externos como Enem, Ideb - Índice de desenvolvimento da Educação Básica -, Saeb - Sistema de Avaliação da Educação Básica-, Saresp - Sistema de Avaliação do Rendimento Escolar do Estado de São Paulo -, Prova Brasil e como prepará-los.

A coleção de Ensino Fundamental I utilizada por nós em 2013 no município de Ourinhos contemplava materiais voltados para cada série do $1^{\circ}$ ao $5^{\circ}$ ano. Com exceção do material do $1^{\circ}$ ano que era volume único, os demais eram divididos por bimestre. Cada bimestre é subdivido em quatro unidades geralmente, totalizando dezesseis unidades curtas, a quarta unidade de cada bimestre é sempre uma revisão das três anteriores. O material é acompanhado por um CD de áudio com canções das unidades didáticas, só disponibilizado para o professor, e há no manual do professor flash cards. O manual do professor apresenta orientações e sugestões de atividades, explicando passo a passo cada exercício e trazendo algumas sugestões de como conduzir a aula; está em língua portuguesa com exceção do insumo linguístico e autoria do material mudava conforme a série.

$\mathrm{Na}$ nossa análise de conteúdos, fomos procurar a presença de gêneros textuais/discursivos na coleção. Podemos apontar que nas apostilas do $1^{\circ}$ e $2^{\circ}$ ano havia a ausência de textos, em que os conteúdos eram somente frases e grupos lexicais. A única exceção eram as canções, que eram criadas para fins exclusivamente didáticos ou eram as nursery rhymes tradicionais, adaptadas ou não. Sobre essas canções, só podem ser encontradas nas apostilas do $1^{\circ}$ ao $3^{\circ}$ ano e geralmente estão relacionadas com o tema da unidade ou com o conteúdo estrutural ou são colocadas sem propósito algum.

Observamos, portanto, uma postura amplamente arraigada no ensino de língua inglesa em geral e também no ensino de LIC em que ensinar a língua é ensinar orações, frases e vocabulários isolados, partindo do pressuposto de que o aluno iniciante não é capaz de confrontar enunciados sociais. Essa progressão da língua está relacionada a uma perspectiva estruturalista de ensino em que parte-se das estruturas sintáticas mais simples para as mais complexas. Em relação ao ensino de LIC e a ensinar crianças em geral, há uma concepção comum de que basta ser lúdico ou abordar algum aspecto do universo infantil para transpor o ensino para essa faixa etária. Isso simplifica a posição do professor de crianças e dista muito da verdadeira realidade da enorme gama de saberes que envolve lecionar para essa faixa etária. E que quanto antes nos 


\title{
XI SEMINÁRIO DE PESQUISA EM CIÊNCIAS HUMANAS - SEPECH \\ Humanidades, Estado e desafios didático-científicos \\ Londrina, 27 a 29 de julho de 2016
}

comprometermos a formar a criança para a cidadania, maiores os benefícios para ela em sua caminhada escolar.

\begin{abstract}
Nessa direção, no que tange mais especificamente a LI no EFI, percebe-se que, por meio dos livros didáticos (LD), são também geralmente privilegiados nas aulas gêneros orais do cotidiano, sendo a maior parte das canções e brincadeiras centradas no ensino do vocabulário e da gramática (Rojo et al, 2009 apud ROCHA, 2009, p. 181).
\end{abstract}

Nas apostilas, os textos aparecem a partir do $3^{\circ}$ ano e são criados pelos autores do material com o propósito de abordar o conteúdo estrutural. $\mathrm{Na}$ apostila do $5^{\mathrm{o}}$ ano, aparecem também textos autênticos adaptados, retirados de sites como na Unit 7 do volume 4 do material do $5^{\circ}$ ano que traz um texto adaptado da internet para falar sobre os grupos alimentares que compõem a pirâmide alimentar (SCHLICHTA, 2011b, vol. 4); ou como a adaptação das característica retiradas de outro site do zodíaco chinês para embasar o conteúdo estrutural sobre descrição de personalidade na Unit 2, volume 3 do $5^{\circ}$ ano (SCHLICHTA, 2011b, vol. 3). No material do $5^{\circ}$ ano, há também a exposição de muitas pinturas que são ora utilizadas para pretexto estrutural ou de reflexão ou ilustração temática.

A prática fomentada pelo material está muito distante do uso de gêneros textuais/discursivos como objeto ou como instrumento de ensino e sim como do texto como pretexto para incutir linguagem proveniente da imitação e da repetição, desprovida de envoltório social e discursivo. O que, consequentemente, priva a criança de galgar novas esferas sociais para o seu próprio crescimento. Sobre o agrupamento de gêneros proposto por Rocha (2010), como já vimos não há abordagem de gêneros que fazem cantar, também não há o trabalho com gêneros que fazem brincar, pois as brincadeiras têm o mesmo propósito estrutural e comportamental e nem gêneros que fazem contar, sendo nula a presença de histórias na coleção.

O outro Sistema investigado por nós é o sistema Anglo de ensino que começou em uma escola como material didático utilizado para um preparatório para o vestibular na década de 1930 na cidade de São Paulo. Sua comercialização mais agressiva inicia na década de 1950. Desde então, tem focado suas estratégia de venda em um calendário estruturado de aulas e a programação pré-estabelecida em que professores e alunos devem seguir religiosamente para que o ensino se dê de forma organizada e eficiente, ensinando o aluno como organizar-se em relação aos seus estudos na sala de aula e fora dela. E também na eficácia em relação à aprovação no vestibular, pois aprova mais que os concorrentes: $50 \%$ e $60 \%$ das vagas das melhores universidades de São Paulo são Anglo. ${ }^{4}$

A coleção analisada é a referente à LI para o EFI, composta de 5 volumes, um para cada série (material anual). Todos eles são acompanhados de um CD de áudio com as canções das apostilas e os áudios para as atividades de compreensão oral, esses tanto para o professor como para o aluno. O livro do $2^{\circ}$ ano possui um Story Time (Hora da História) com atividades sobre a história "The Little Mermaid" (A Pequena Sereia), acompanhada de cartazetes (o nome do recurso está conforme o material) que são enviados ao professor. Há também cartazetes sobre animais selvagens, sentimentos,

\footnotetext{
${ }^{4}$ Informação retirada do site: http://www.abrileducacao.com.br/descricao_anglo.html
} 


\section{SEMINÁRIO DE PESQUISA EM CIÊNCIAS HUMANAS - SEPECH \\ Humanidades, Estado e desafios didático-científicos \\ Londrina, 27 a 29 de julho de 2016}

alimentos, fazenda, cidade e praia que acompanham a coleção. Apenas o material do $1^{\circ}$ ano possui flash cards para o professor.

O material possui a mesma autoria ao longo das séries, salvo o material do $2^{\circ}$ ano que conta com mais duas autoras. O manual do professor contempla os benefícios de se estudar uma língua estrangeira, a natureza do aprendiz criança, as habilidades e objetivos enfatizados, os deveres do professor, o conteúdo temático, as personagens, os gêneros abordados, a natureza das diferentes atividades, orientações metodológicas, referência aos outros recursos que compõem o material.

Da mesma maneira, que na Coleção Expoente, procuramos pela presença de gêneros textuais/discursivos. Todavia, diferentemente da primeira, no manual do professor havia a alegação de que o material trabalhava com gêneros. Compilamos na forma de um quadro os gêneros que cada manual do professor referente a cada série atestava que estava contemplado no livro do aluno:

\begin{tabular}{|c|c|}
\hline Série & Gêneros \\
\hline $\begin{array}{l}1^{\circ} \text { ano (LEDERMAN, POTTER, 2010a, p. } \\
07 \text { ) }\end{array}$ & $\begin{array}{l}\text { Diálogos, histórias em quadrinhos, } \\
\text { músicas, chants }{ }^{5} \text {, instruções. }\end{array}$ \\
\hline $2^{\circ}$ ano (LEDERMAN et al., 2005a, p. 06) & $\begin{array}{l}\text { Diálogos, leitura e escrita de cartões- } \\
\text { postais, cartões comemorativos, receitas, } \\
\text { listas de compras de supermercado, } \\
\text { gráficos, trava-línguas, músicas, } \\
\text { entrevistas, instruções. }\end{array}$ \\
\hline $\begin{array}{l}3^{\circ} \text { ano (LEDERMAN, POTTER, 2006a, p. } \\
05 \text { ) }\end{array}$ & $\begin{array}{l}\text { Diálogos, leituras, cartões comemorativos, } \\
\text { receitas, gráficos, trava-línguas, músicas, } \\
\text { entrevistas, instruções. }\end{array}$ \\
\hline $\begin{array}{l}4^{\circ} \text { ano (LEDERMAN, POTTER, 2007a, p. } \\
05 \text { ) }\end{array}$ & $\begin{array}{l}\text { Diálogos, leituras, cartões comemorativos, } \\
\text { textos jornalísticos, trava-línguas, músicas, } \\
\text { entrevistas, instruções. }\end{array}$ \\
\hline $\begin{array}{l}5^{\circ} \text { ano (LEDERMAN, POTTER, 2007b, p. } \\
05 \text { ) }\end{array}$ & $\begin{array}{l}\text { Diálogos, leituras, cartões comemorativos, } \\
\text { histórias em quadrinhos, folhetos, trava- } \\
\text { línguas, músicas, entrevistas, instruções. }\end{array}$ \\
\hline
\end{tabular}

Quadro 6 - Gêneros apresentados no manual do professor na Coleção Anglo (MORENO, 2014, p. 120)

Antes de entrarmos no mérito de encontrar os gêneros no livro do aluno, a primeira confusão se faz na forma como alguns textos estão nomeados pelo manual e se são, de fato, nomes de gêneros existentes. Estamos falando aqui de "diálogos" e "leituras", que não são gêneros propriamente ditas, já que de acordo com os PCN (BRASIL, 1998, p. 22) "gêneros são famílias de textos que compartilham características comuns". Questionamos, então, quais seriam as características comuns para os gêneros "leitura e diálogo", já que muitos gêneros podem ser lidos e dialogados. Entrevê-se aí o desconhecimento da teoria de algo postulado no manual do professor. $\mathrm{Na}$ mesma questão, entra a "leitura e escrita de cartões-postais", que demonstra a dificuldade de definição de um gênero confundindo-o com as habilidades da língua.

\footnotetext{
${ }^{5}$ Chants, neste caso, são versos infantis entoadas com um ritmo que não chega a caracterizar uma canção. Ex.: Pat-a-cake, Fuzzy Uzzy, etc. Em Português, algumas parlendas poderiam ser caracterizadas como chants.
} 


\section{SEMINÁRIO DE PESQUISA EM CIÊNCIAS HUMANAS - SEPECH \\ Humanidades, Estado e desafios didático-científicos \\ Londrina, 27 a 29 de julho de 2016}

Servindo-nos, então, da comparação com o livro do aluno, percebemos que o que as autoras definem como gênero "diálogo" nada mais é do que as inúmeras situações artificiais criadas para exercitar estruturas prontas na oralidade. As histórias em quadrinhos mencionadas no $1^{\circ}$ e $5^{\circ}$ ano são situações criadas em que os personagens do livro exercitam estruturas como é o caso no $1^{\circ}$ ano (LEDERMAN, POTTER, 2010b) ou que eles trazem informações sobre o tópico abordado como no $5^{\circ}$ ano sobre fósseis e mamíferos (LEDERMAN, POTTER, 2007c). Interessante é que na apostila do $4^{\circ}$ ano trabalha-se com uma tira da Turma da Mônica para praticar as estruturas de Present Continuous nas terceiras pessoas, porém no manual desta série não é mencionado o gênero história em quadrinhos, mesmo sendo um texto autêntico -, claro que não abordado como gênero.

As músicas são criadas, adaptadas e autênticas (nursery rhymes e de bandas e cantores famosos). Da mesma forma que a Coleção Expoente, estão nas unidades pela relação temática ou exercitação de estruturas. Também há aquelas que estão descontextualizadas e sem relação nenhuma com o todo. As instruções a que os manuais referem-se provavelmente são os enunciados em LI dos exercícios. Os demais textos: cartões-postais, cartões comemorativos, receitas, listas de copras de supermercado, gráficos, trava-línguas, entrevistas, folhetos são trabalhados como forma de exercitação de léxico e estrutura sem abordar em nenhum momento a organização composicional dos gêneros e a situação comunicativa imediata. Alguns gêneros nem são trabalhados em suas características linguísticas, são só extensões de outras atividades como cartões comemorativos, gráficos, trava-línguas e entrevistas.

O chamado gênero texto jornalístico (que não sabemos se é reportagem, notícia, etc.) parece se referir a uma página de um website de uma seção de esportes de um jornal australiano, mesmo assim uma seção de esportes é bem diferente das características que definem o gênero pertencente à esfera jornalística. $\mathrm{O}$ que os manuais chamam de gênero leitura parece ser uma série de textos fabricados criados para fim de explorar o conteúdo estrutural, assim como os demais mencionados. Alguns inclusive imitam gêneros existentes: blog, web page, texto informativo, pirâmide alimentar, informação nutricional, autobiografia, flog, texto de opinião, que não são mencionados no manual.

Nessa coleção, fica claro como os conteúdos acadêmicos, adentram as salas de aula como "modismos" em que suas nomenclaturas são utilizadas para maquiar os velhos conteúdos estruturais. Diferentemente, de um livro didático que passa pelo crivo da avaliação do PNLD (Programa Nacional do Livro Didático), os Sistemas Apostilados de Ensino são eximidos dessa avaliação teórico-metodológica, o que não cria a exigência de um sólido arcabouço que esteja por trás da coleção. Há brincadeiras, canções e uma história "The little mermaid", porém não há gêneros que fazem brincar, cantar e contar, pois os propósitos e contextualização dos textos são outros: o trabalho com conteúdos estruturais da língua.

\section{CONSIDERAÇÕES FINAIS}

O objetivo desse artigo foi analisar os conteúdos de LIC em duas coleções de Sistemas Apostilados de Ensino. De acordo com os teóricos da Linguística Aplicada, os conteúdos deveriam ser ou ser organizados a partir de gêneros textuais/discursivos provenientes de esferas da comunicação relacionadas ao universo infantil. Como se 


\section{SEMINÁRIO DE PESQUISA EM CIÊNCIAS HUMANAS - SEPECH \\ Humanidades, Estado e desafios didático-científicos \\ Londrina, 27 a 29 de julho de 2016}

pode constatar, no entanto, os conteúdos estavam muito mais elencados em um eixo estrutural e audiolinguista da língua, focando-se no ensino de palavras isoladas, estruturas da língua, repetição de estruturas através de canções e brincadeiras, cantar e brincar despropositadamente, o uso do texto como pretexto e a leitura decodificadora de textos.

Os gêneros textuais/discursivos fomentam práticas centradas nos letramentos múltiplos, já que possibilitam à criança o contato com a cultura letrada e com outros textos multissemióticos permeados pelas leituras globais, consequentemente com a transculturalidade, permitindo dialogar e se reiterar no eu e no outro e a agentividade, por fomentar práticas que levam a criança a agir e transformar sua realidade. As discussões sobre gêneros já estão presentes não só na Universidade como no universo escolar de várias formas, porém isso não implica, de fato, a didatização dos gêneros na sala de aula através dos materiais didáticos.

Dessa maneira, as editoras e autores de LDs, procurando agradar os destinatários, vão buscar, nas "novas" teorias sobre aprendizagem e ensino, argumentos que reforcem a qualidade do novo produto, sem contudo, se preocuparem se estão criando algo de tão novo assim (...) o novo se constrói pelo retorno do já-dito (FOUCAULT, 1971, 28 apud CORACINI, 1999, p. 21)

Com isso, preocupa-nos a qualidade do ensino de LIC que está presente nas escolas em um cenário em que não há uma responsabilidade autêntica por parte das coleções com as teorias e práticas que acarrete aprendizagem significativa para as crianças. Principalmente em salas de aula de LIC, pois são poucos professores que têm um olhar crítico sobre o material didático utilizado e que são criadores ou adaptadores de material didático, ainda mais em um contexto tão carente de formação. Ou ainda se é lhes é permitido romper com o material em situações de uso dos Sistemas Apostilados de Ensino. O nosso convite, ao final dessa pesquisa, é que continuemos a zelar e a lutar como professores e pesquisadores pela qualidade do ensino de LIC para que esse cumpra os propósitos emancipadores e transformadores potencialmente incutidos no mesmo.

\section{REFERÊNCIAS}

BRASIL. Parâmetros curriculares nacionais: língua portuguesa: $5^{\mathrm{a}}$ a $8^{\mathrm{a}}$ séries. Brasília: Secretaria de Educação Fundamental, 1998.

CARMAGNANI, Anna Maria. Ensino apostilado e a venda de novas ilusões. In: CORACINI, Maria José Rodrigues Faria (Org.). Interpretação, autoria e legitimação do livro didático: língua materna e língua estrangeira. Campinas: Pontes, 1999. p. 45-55

CHIMELO, Juliane Zonaro; BUNZEN, Clecio. Sistema apostilado e ensino de leitura para as crianças do $2^{\circ}$ ano nos municípios paulistas. Revista contemporânea de Educação, Rio de Janeiro, n. 12, ago./dez. 2011. p. 36-60. 


\section{SEMINÁRIO DE PESQUISA EM CIÊNCIAS HUMANAS - SEPECH \\ Humanidades, Estado e desafios didático-científicos \\ Londrina, 27 a 29 de julho de 2016}

CORACINI, Maria José R. Faria. O Livro didático nos discursos da linguística aplicada e de sala de aula. In: CORACINI, Maria José R. Faria (Org.). Interpretação, autoria e legitimação do livro didático: língua materna e língua estrangeira. Campinas: SP, Pontes, 1999. p. 17-26.

CRISTOVÃO, Vera Lúcia Lopes; GAMERO, Raquel. Brincar aprendendo ou aprender brincando? O inglês na infância. Trabalhos em Linguística Aplicada, Campinas, v. 48, n. 2, p. 229-245, jul./dez. 2009.

GIMENEZ, Telma. Apresentação. In: ROCHA, Claudia Hilsdorf; TONELLI, Juliana Reichert Assunção; SILVA, Kleber Aparecido da (Org.). Lingua estrangeira para crianças: ensino-aprendizagem e formação docente. Campinas: Pontes, 2010. p. 13-25. (Novas Perspectivas em Linguística Aplicada, v. 7).

LEDERMAN, Ligia et al. English 2: ensino fundamental - manual do professor. São Paulo: Anglo, 2005a

LEDERMAN, Ligia; POTTER, Louise Emma. English 1: ensino fundamental - manual do professor. São Paulo: Anglo, 2010a.

.English 1: ensino fundamental. São Paulo: Anglo, $2010 \mathrm{~b}$.

. English 3: ensino fundamental - manual do professor. São Paulo: Anglo, 2006a.

LEDERMAN, Ligia; POTTER, Louise Emma. English 4: ensino fundamental - manual do professor. São Paulo: Anglo, 2007a.

. English 5: ensino fundamental - manual do professor. São Paulo: Anglo, $2007 b$

English 5: ensino fundamental. São Paulo: Anglo, 2007c.

LIMA, Ana Paula de. Análise de propostas de avaliação de rendimento em livros didáticos de inglês para o ensino fundamental I. 2011. 135 f. Dissertação (Mestrado em Linguística Aplicada) - Instituto de Estudos da Linguagem, Universidade Estadual de Campinas, Campinas, 2011.

MORENO, Ticiane Rafaela de Andrade. Read and copy: o ensino de língua inglesa para crianças nos sistemas apostilados de ensino. 2014. 146 f. Monografia (Especialização 


\section{SEMINÁRIO DE PESQUISA EM CIÊNCIAS HUMANAS - SEPECH \\ Humanidades, Estado e desafios didático-científicos \\ Londrina, 27 a 29 de julho de 2016}

em Ensino de Línguas Estrangeiras) - Universidade Estadual de Londrina, Londrina, 2014.

RAMOS, Rosinda Castro Guerra. O livro didático de língua inglesa para o ensino fundamental e médio: papeis, avaliação e potencialidades. In: CRISTOVÃO, Vera Lúcia Lopes; DIAS, Reinildes (Org.). O livro didático de língua estrangeira: múltiplas perspectivas. Campinas: Mercado das Letras, 2009. p. 173-198.

; ROSELLI, Bernadette Rodriguez. O livro didático e o ensino-aprendizagem de inglês para crianças. In: ROCHA, Cláudia Hilsdorf; BASSO, Edcleia Aparecida (Org.). Ensinar e aprender línguas estrangeiras nas diferentes idades: reflexões para professores e formadores. São Carlos: Claraluz, 2008. p. 63-84.

REIS, Simone. Reflexões sobre uma jornada com destino à pesquisa. In: GIMENEZ, Kilda (Org.). Contribuições na área de línguas estrangeiras. Londrina: Moriá, 2005. p. 75-90.

ROCHA, Cláudia Hilsdorf. O ensino de línguas para crianças no contexto educacional brasileiro: breves reflexões e possíveis provisões. DELTA, São Paulo, v. 23, n. 2, 2007a. p. 273-319.

O ensino de LE (Inglês) para crianças no ensino fundamental público na transdisciplinaridade da linguística aplicada. In: TONELLI, Juliana Reichert Assunção; RAMOS, Samantha Gonçalves Mancini (Org.). O ensino de LE para crianças: reflexões e contribuições. Londrina: Moriá, 2007b. p. 1-34

O ensino de línguas para crianças: refletindo sobre princípios e práticas. In: ROCHA, Cláudia Hilsdorf; BASSO, Edcleia Aparecida (Org.). Ensinar e aprender linguas estrangeiras nas diferentes idades: reflexões para professores e formadores. São Carlos: Claraluz, 2008. p. 15-34.

O inglês no ensino fundamental I público sob perspectivas Bakhtinianas. Anais do Seta, Campinas, n. 3, p. 171-187, 2009.

Propostas para o inglês no ensino fundamental I público: plurilinguismo, transculturalidade e multiletramentos. 2010. Tese (Doutorado em Linguística Aplicada) - Instituto de Estudos da Linguagem, Universidade Estadual de Campinas, Campinas, 2010 .

SANTOS, Leandra Ines Seganfredo. Presença da LE na sociedade em contexto de ensino regular público. In: ROCHA, Claudia Hilsdorf; TONELLI, Juliana Reichert 


\section{SEMINÁRIO DE PESQUISA EM CIÊNCIAS HUMANAS - SEPECH \\ Humanidades, Estado e desafios didático-científicos \\ Londrina, 27 a 29 de julho de 2016}

Assunção; SILVA, Kleber Aparecido da (Org.). Língua estrangeira para crianças: ensino-aprendizagem e formação docente. Campinas: Pontes, 2010. p. 149-184. (Novas Perspectivas em Linguística Aplicada, v. 7).

SCLICHTA, Angela Márcia. Ensino Fundamental - Língua Inglesa: $5^{\circ}$ ano. Curitiba: Expoente, 2011b. v. 1, 2, 3, 4

TÍLIO, Rogério; ROCHA, Cláudia Hilsdorf. As dimensões da linguagem em livros didáticos de inglês para o ensino fundamental I. Trabalhos em Linguística Aplicada, v. 48, n. 2, p. 295-315, jul./dez. 2009.

TONELLI, Juliana Reichert Assunção. Histórias infantis e o ensino de língua inglesa para crianças. In: ROCHA, Cláudia Hilsdorf; BASSO, Edcleia Aparecida (Org.). $O$ ensino de LE para crianças: reflexões e contribuições. Londrina: Moriá, 2007. p. 107136 